«Системні технології» 1 (126) 2020 «System technologies»

DOI 10.34185/1562-9945-1-126-2020-16

УДК 004.9: 528.8

I.M. Гаркуша, В.В. Гнатушенко

\title{
ІНФОРМАЦІЙНА ТЕХНОЛОГІЯ СТВОРЕННЯ БЕЗШОВНОЇ МОЗАЇКИ ЗА РАДАРНИМИ КОСМІЧНИМИ ЗОБРАЖЕННЯМИ
}

Анотація. У даній роботі представлена інформаційна технологія побудови безшовної мозаїки супутникових радіолокаційних сцен. Представлені ключові моменти, пов'язані з технологією підготовки сцен Sentinel-1 для побудови мозаїки. Показані результати роботи методу на фрагменті мозаїки Антарктиди. Для зменшення обчислювальних витрат, сцени для мозаїки Антарктики були приведені до просторової здатності 120 метрів і представлені в проекції WGS-84 / Antarctic Polar Stereographic. В процесі побудови мозаїки встановлено, що EW-зйомка в повному обсязі не покриває берегову лінію. Тому для заповнення прогалин було використані додатково дані в режимі зйомки Interferometric Wide Swath (IW), продукт Level-1 GRD в High Resolution - GRDH-nродукт з просторовою здатністю 10 метрів, який ресемпльовано до розрізнення 120 метрів. Експерименти підтвердили, що технологія дозволяє домогтися автоматичної панорамної мозаїки зони iнmересу.

Ключові слова: мозаїка, Антарктида, радіолокаційне зображення, блендінг, поляризація, зшивання.

Вступ. Багато років людство вивчає шостий континент планети Антарктиду. Дослідження Антарктики ведуться вченими різних країн, частина з яких має свої, спеціально створені для експедицій, дослідні станції. Також багато вчених працює в міжнародних проектах, використовуючи обладнання та ресурси цих станцій. Проводяться найрізноманітніші дослідження - кліматичні, геологічні, льодові, тваринного і рослинного світів і інші. Одними 3 найважливіших факторів, що впливають на планету в цілому і на континент зокрема, $є$ процеси руйнування льодового покриву Антарктиди. 3 запуском сучасних космічних апаратів, моніторинг танення льодовиків і зміни берегової лінії Антарктиди проводиться практично цілодобово. Однак, є складнощі в процесі моніторингу Антарктиди. Часто дані супутникової зйомки, зважаючи на їх високу періодичність поблизу полюса, залишаються по-

(C) Гаркуша I.M., Гнатушенко В.В., 2020 
«Системні технологіï» 1 (126) 2020 «System technologies»

гано вивченими. Одна з причин - їх велика кількість. Крім того, досить часто багатьох вчених цікавлять тільки певні області Антарктиди $[1,2]$. Іншим фактором, що впливає на отримання інформації про стан льодового покриття континенту, є погода. Атмосферні маси, які скупчуються над континентом і поблизу нього, не дозволяють бачити відповідні зміни в оптичному діапазоні. Тоді на допомогу дослідникам приходить радарна зйомка.

Аналіз останніх досліджень. Радарні знімальні системи проводять активну зйомку, оскільки самі є джерелами сигналу. 3 огляду на фізичні особливості радарної зйомки, вона $є$ всепогодною і не залежить від часу доби і сезонів. 3 кінця 2014 року періодичну зйомку прибережної частини Антарктиди проводить супутник Європейського космічного агентства (ESA) Sentinel-1A. Зйомка проводиться в С-діапазоні частот сантиметрових хвиль електромагнітного спектра на частоті 5.405 ГГц. У 2016 році другий апарат cepiï Sentinel-1 доповнив зйомку і підвищив їі періодичність. На сьогоднішній день пара апаратів Sentinel-1A/B дозволяє отримувати знімки 3 періодичністю в 5-6 днів по багатьом ділянкам антарктичного узбережжя [3]. Сьогодні створено кілька продуктів-мозаїк льодового покриву Антарктиди. Найбільш відомими серед них $€$ :

1. Продукт The National Snow and Ice Data Center (NSIDC) - RAMP AMM-1 SAR Image Mosaic of Antarctica, Version 2. Його особливістю $є$ те, що продукт виконаний у вигляді декількох варіантів з різною просторовою здатністю: 25 метрів (окремими фрагментами), 125, 200, 500 метрів і 1 км. Його основною відмінністю є те, що мозаїка як продукт створена на початку 2000 років, періодично поліпшується за якістю. Однак, вона не є різночасовою [4]. Дані для побудови мозаїки були отримані в процесі Antarctic Mapping Mission (AMM-1) з апарату RADARSAT-1 в 1997 році. Зйомка велася в спеціальному режимі роботи RADARSAT-1, що дозволило зафіксувати протягом 18 днів всю територію Антарктиди.

2. Продукти NSIDC and the University of New Hampshire - MODIS Mosaic of Antarctica 2003-2004 (MOA2004) [5] i MODIS Mosaic of Antarctica 2008-2009 (МОА2009) [6]. Цей продукт виконаний по зйомках сканера 
MODIS з платформ Aqua i Terra. Мозаїка за 2009 рік представлена в просторовому розрізненні 125 і 750 метрів. Додатковими даними в продукті йдуть векторні границі берегової лінії і островів.

3. Мозаїки на основі зйомок MODIS, що надаються сервісом Polar View (https://www.polarview.aq/antarctic).

Формулювання цілей статті. Метою роботи $є$ створення інформаційної технології побудови безшовної мозаїки супутникових різночасових радіолокаційних сцен.

Основна частина. Основними джерелами вихідних даних для побудови мозаїки були спеціалізовані пошукові сервіси:

- Copernicus Open Access Hub (https://scihub.copernicus.eu/);

- ASF Data Search Vertex (https://search.asf.alaska.edu/);

- Polar View (https://www.polarview.aq/antarctic).

Основними критеріями пошуку продуктів Sentinel-1 в Copernicus Open Access Hub є діапазон дат зйомок, область інтересу (AOI) i relative orbit. Значення останнього параметра коливаються від 1 до 175. Пошукова система ASF Data Search Vertex передбачає ще один додатковий критерій пошуку - Frame, a relative orbit замінений на параметр Path. Як зазначено в описі до Vertex, всім сценам в архіві зйомок за певним алгоритмом присвоюється значення Frame. Цей додатковий параметр дозволяє швидко шукати сцени, що покривають зйомкою одну й ту ж саму територію планети із заданою періодичністю. Зазначені дві системи пошуку продуктів Sentinel-1 пропонують користувачам також спеціальні пошукові API. В якості основного продукту для побудови мозаїки Антарктики, обраний режим зйомки Extra Wide Swath (EW), продукт Level-1 Ground Range Detected (GRD) в Medium Resolution - GRDM-продукт з просторовою здатністю 40 метрів. Для зменшення обчислювальних витрат, сцени для мозаїки Антарктики були приведені до просторової здатності 120 метрів і представлені в проекції WGS-84 / Antarctic Polar Stereographic (EPSG: 3031). В процесі побудови мозаїки встановлено, що EW-зйомка в повному обсязі не покриває берегову лінію. Тому для заповнення прогалин було використані додатково дані в режимі зйомки Interferometric Wide Swath (IW), продукт Level-1 GRD в High Resolution - GRDH-продукт 3 
«Системні технології» 1 (126) 2020 «System technologies»

просторовою здатністю 10 метрів, який ресемпльовано до розрізнення 120 метрів. Таким чином, після відбору сцен-кандидатів на побудову мозаїки берегової лінії Антарктиди було відібрано 87 GRDM і 11 GRDH Level-1 продуктів Sentinel-1. Оскільки не у всіх Path / Frame сцени мали дві поляризації НH і HV, то в якості основної обрана поляризація НН. В основі технології збору даних лежали наступні кроки.

1. Встановлення діапазону дат для складання мозаїки.

2. Складання списку сцен.

3. Визначення меж сцен для складання mosaic coverage.

4. Складання списку сцен mosaic coverage.

5. Завантаження сцен зі списку mosaic coverage.

6. Передобробка GRD-продуктів Sentinel-1.

7. Зшивка сцен в єдину мозаїку на основі списку сцен і преобработанних растрів.

В якості вихідних сцен для мозаїки обрані сцени з датами зйомок між 20190427 і 20190517 (всього 94 сцени). Зйомка території по 4 сценам не потрапляла в цей часовий інтервал. Оскільки Sentinel-1 знімає деякі ділянки берегової лінії Антарктиди нерегулярно, то за цими 4 дільницями мозаїки були обрані найближчі дати зйомок. При цьому було виявлено, що дві найближчі сцени 3 98, що увійшли в мозаїку як найближчі до заданого діапазону, датовані серединою червня 2018 року. Ці локації представлені жовтим кольором на рис. 1. Діапазон зазначених дат був обраний за базовий. Це дозволило в подальшому використовуючи значення Path / Frame відбирати з інтервалом 12 днів нові сцени, просуваючись до кінця 2019 року. Таким чином, використовуючи створене покриття для мозаїк і складаючи кожен раз новий список сцен, відштовхуючись від базових дат, були створені 7 мозаїк. В ході аналізу побудованих 7 мозаїк визначена частота зміни сцен по кожному фрагменту (рис.2). Із зібраної статистики встановлено, що 63\% сцен змінювалося в мозаїці. Ще 8\% змінювалося на 6 мозаїках. 21\% сцен був незмінний. Тобто це сцени, які не змінювалися протягом часу, відведеного для побудови всіх 7 мозаїк. Внаслідок цього, в мозаїку були прийняті сцени, що увійшли в попередні мозаїки. Таким чином, 71\% 
«Системні технології» 1 (126) 2020 «System technologies»

створеного покриття Антарктиди при циклічній зміни сцен добре відображає зміни в береговій лінії материка в часі.

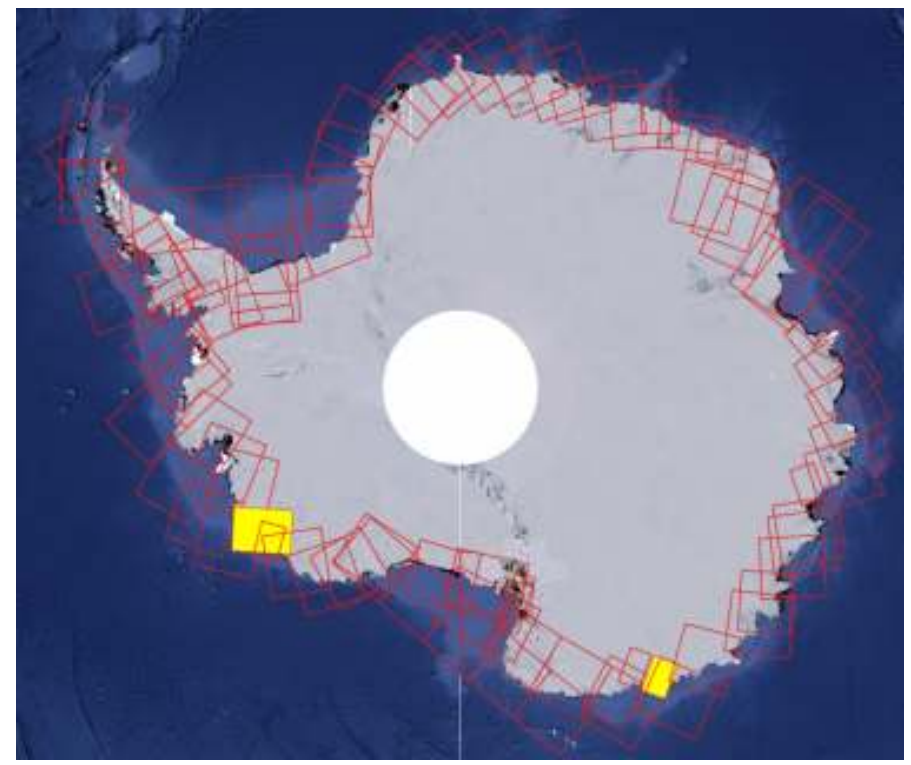

Рисунок 1 - Покриття сценами Sentinel-1 берегової частини Антарктиди

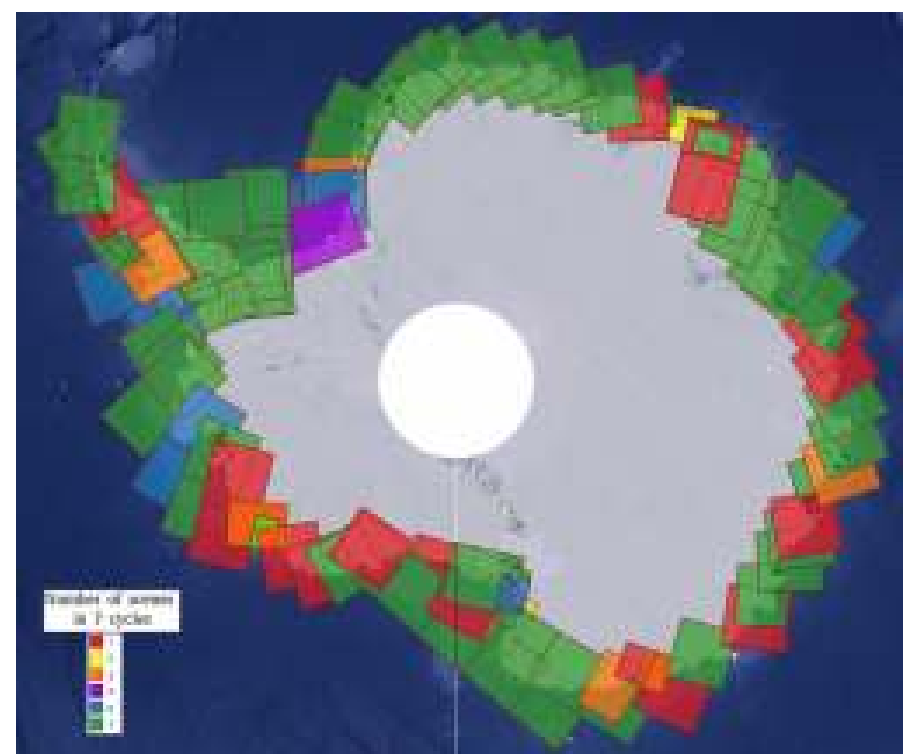

Рисунок 2 - Частота оновлення сцен при побудові 7 мозаїк за певним покриттям

Мозаїка будується послідовним злиттям пар сцен (рис.3а) зі списку покриття. Причому перша сцена кожної пари, за винятком першої пари, сама є мозаїкою. В основі методу зшивання сцен в мозаїку лежить процес геометричного аналізу розташування пікселів, що потрапили в перекриття сцен. Як зазначено в роботах [7-9], подібний аналіз є 
найбільш поширеним і демонструє гарні результати на сценах, що мають невеликі часові відмінності в поданні території.

Однак, як показав ряд експериментів, математичні моделі для реалізації мозаїки з великих за розмірами сцен, з великою кількістю пікселів, що потрапили в перекриття сцен, працюють досить довго. Зважаючи на це, нами в роботі використана наступна модель, що заснована на традиційній моделі блендінга зображень:

$$
\begin{gathered}
k(x)=\left|x-x_{1}\right| /\left|x_{2}-x_{1}\right| \\
f_{m}(x, y)=\sqrt{k}(x) * f_{1}(x, y)+(1-k(x)) * f_{2}(x, y) 7
\end{gathered}
$$

де $f_{1}(x, y)$ и $f_{2}(x, y)$ - відповідно праве і ліве вихідні зображення, $f_{m}(x, y)$ - зображення мозаїки, Г. - приведення до цілого. Коефіцієнт $k(x)$ - це коефіцієнт блендінга, який в роботі обчислювався як залежність координати пікселя растра по $x$ від його місця розташування в рядку ділянки перекриття. $x_{1}$ та $x_{2}-$ значення координати х початку і кінця деякого рядка в ділянці перекриття сцен. Для прискорення процесу аналізу ділянки перекриття використаний підхід порядкового сканування.

Дана модель не вимагає великих обчислювальних витрат на визначення значення коефіцієнта $k(x)$, що при використанні певних структур даних дає виграш у швидкодії. Результат перетворення (1) для трьох фрагментів мозаїки Антарктиди представлений на рис. 36.

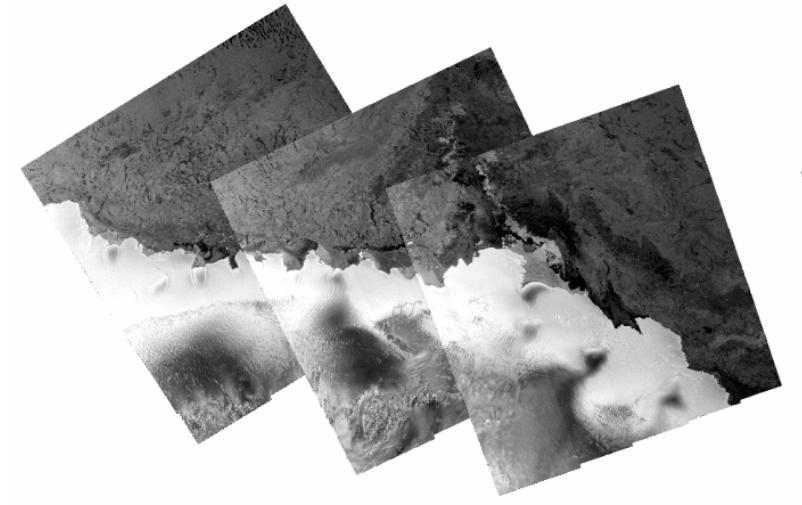

a)

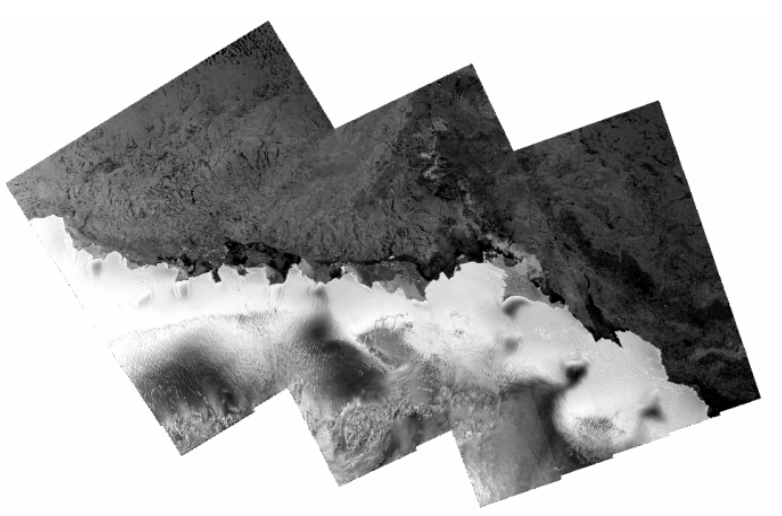

б)

Рисунок 3 - Результат зшивання трьох фрагментів мозаїки:

а) вихідні сцени; б) сцени після перетворення

Висновки. Візуалізація декількох радарних різночасових мозаїк дозволяє значно підвищити спостереження льодового покриття. Запропонований метод зшивання радарних зображень показав гарні результа- 
«Системні технології» 1 (126) 2020 «System technologies»

ти при створенні мозаїки Антарктиди. У методі виконувалося сканування по рядках перекриття зображень. Також в ході експериментів виконувалося сканування за стовпцями. Однак ця операція не покращила загальну якість мозаїки. Можлива доробка методу з урахуванням меж перекриттів за умови використання ефективних структур даних для виконання обчислювальних алгоритмів.

\section{ЛІТЕРАТУРА/ ЛИТЕРАТУРА}

1. Baumhoer Celia A., Dietz Andreas J., C. Kneisel, Kuenzer C. Automated Extraction of Antarctic Glacier and Ice Shelf Fronts from Sentinel-1 Imagery Using Deep Learning, Remote Sens. 2019, 11(21), 2529.

2. Fürst J.J., Durand G., Gillet-Chaulet F., Tavard L., Rankl M., Braun M., Gagliardini $O$. The safety band of Antarctic ice shelves, Nat. Clim. Chang. 2016, 6, 479-482.

3. Copernicus Open Access Hub. Available online:

https://scihub.copernicus.eu/ (accessed on 28 November 2019).

4. Jezek K.C., Curlander J.C., Carsey F., Wales C., Barry R. G. RAMP AMM-1 SAR Image Mosaic of Antarctica. Version 2. Boulder, Colorado USA. NSIDC: National Snow and Ice Data Center, 2013.

https://doi.org/10.5067/8AF4ZRPULS4H.

5. Haran T., Bohlander J., Scambos T., Painter T., Fahnestock M. MODIS Mosaic of Antarctica 2003-2004 (MOA2004) Image Map. Boulder, Colorado USA: National Snow and Ice Data Center, 2005.

http://dx.doi.org/10.7265/N5ZK5DM5.

6. Haran T., Bohlander J., Scambos T., Painter T., Fahnestock M. MODIS Mosaic of Antarctica 2008-2009 (MOA2009) Image Map. Boulder, Colorado USA: National Snow and Ice Data Center, 2014.

http://dx.doi.org/10.7265/N5KP8037.

7. Yang Y., Gao, Y., Li H., Han Y. An Algorithm for Remote Sensing Image Mosaic Based on Valid Area. In: 2011 International Symposium on Image and Data Fusion (ISIDF 2011). IEEE, Piscataway, 2011.

8. Lu T., Li S., Fu W. Fusion Based Seamless Mosaic for Remote Sensing Images. In.:Sens Imaging,2014,15:101.https://doi.org/10.1007/s11220-014-0101-0. 9. Luo Yi, Flett Dean. Sentinel-1 data border noise removal and seamless SAR mosaic generation, Proceedings, 2018, 2(7), 330. doi:10.3390/ecrs-2-05143. 


\section{REFERENCES}

1. Baumhoer Celia A., Dietz Andreas J., C. Kneisel, Kuenzer C. Automated Extraction of Antarctic Glacier and Ice Shelf Fronts from Sentinel-1 Imagery Using Deep Learning, Remote Sens. 2019, 11(21), 2529.

2. Fürst J.J., Durand G., Gillet-Chaulet F., Tavard L., Rankl M., Braun M., Gagliardini $O$. The safety band of Antarctic ice shelves, Nat. Clim. Chang. 2016, 6, 479-482.

3. Copernicus Open Access Hub. Available online:

https://scihub.copernicus.eu/ (accessed on 28 November 2019).

4. Jezek K.C., Curlander J.C., Carsey F., Wales C., Barry R. G. RAMP AMM-1

SAR Image Mosaic of Antarctica. Version 2. Boulder, Colorado USA. NSIDC:

National Snow and Ice Data Center, 2013.

https://doi.org/10.5067/8AF4ZRPULS4H.

5. Haran T., Bohlander J., Scambos T., Painter T., Fahnestock M. MODIS Mosaic of Antarctica 2003-2004 (MOA2004) Image Map. Boulder, Colorado USA: National Snow and Ice Data Center, 2005.

http://dx.doi.org/10.7265/N5ZK5DM5.

6. Haran T., Bohlander J., Scambos T., Painter T., Fahnestock M. MODIS Mosaic of Antarctica 2008-2009 (MOA2009) Image Map. Boulder, Colorado USA: National Snow and Ice Data Center, 2014.

http://dx.doi.org/10.7265/N5KP8037.

7. Yang Y., Gao, Y., Li H., Han Y. An Algorithm for Remote Sensing Image Mosaic Based on Valid Area. In: 2011 International Symposium on Image and Data Fusion (ISIDF 2011). IEEE, Piscataway, 2011.

8. Lu T., Li S., Fu W. Fusion Based Seamless Mosaic for Remote Sensing Images In.:Sens Imaging,2014,15:101.https://doi.org/10.1007/s11220-014-0101-0. 9. Luo Yi, Flett Dean. Sentinel-1 data border noise removal and seamless SAR mosaic generation, Proceedings, 2018, 2(7), 330. doi:10.3390/ecrs-2-05143.

Received 28.01.2020. Accepted 30.01.2020.

\section{Информационная технология создания бесшовной разновременной мозаики} по радарным космическим изображениям

В данной работе представлена информационная технология построения бесшовной мозаики спутниковых радиолокационных сцен. Представлены ключевые моменты, связанные с технологией подготовки сиен Sentinel-1 для построения мозаики Антарктиды. Для уменьшения вычислительных затрат сцены были приведены к пространственному разрешению 120 метров и представлены в проекции WGS 84 / Antarctic Polar Stereographic. B процессе построения мозаики установлено, что EW-съемка в полном объеме не покрывает береговую линию, поэтому для восполнения пробелов были использованы дополнительно данные в режиме съемки Interferometric Wide Swath, продукт Level-1 GRD в High Resolution с пространственным разрешением 10 метров, который ресемплирован к разршению 120 метров. Эксперименты подтвердили, что технология позволяет добиться автоматической панорамной мозаики зоны интереса. 
«Системні технології» 1 (126) 2020 «System technologies»

The Information technology for building a seamless multi-temporal mosaic from radar space images

One of the most important factors influencing the planet as a whole and the continent in particular is the processes of destruction of the Antarctic ice sheets. Remote sensing images have become an important means of information acquisition. Visualization of several radar mosaics for different time substantially enhances observation of the ice sheets by showing dynamics of development of cracks, motion of icebergs, directions of streams near the surface of water along the coastline and dynamics of the ice field. This work presents the information technology of building a seamless imagery mosaic coverage of satellite radar scenes. The data under consideration are level-1 ground range detected Sentinel-1 products with dualpolarisation. Since not in all Path/Frame combinations scenes had two polarizations, $\mathrm{HH}$ and $\mathrm{HV}$, polarization $\mathrm{HH}$ was chosen as the main one. As the direction of imaging, both ascending and descending scenes were chosen. For decreasing the volume of computations, scenes for the mosaic of Antarctica resampled to the spatial resolution of 120 meters and presented in the WGS-84 / Antarctic Polar Stereographic projection. $71 \%$ of the created coverage of Antarctica, when scenes are cyclically changed, reflects the changes in time of the coastline of the continent well. The key points related to the technology of preparation of the Sentinel-1 scenes for building the mosaic are presented. The first scene in each pair, save for the first pair, is a mosaic in itself. The method of stitching of the scenes into a mosaic is based on the process of geometric analysis of location of pixels overlapping in the scenes. The main results are shown in a fragment of the mosaic coverage of Antarctica. Experiments show that the technology can achieve automatic panoramic mosaic of the survey area.

Гаркуша Ігор Миколайович - к.т.н., доцент, доцент кафедри інформаційних систем та технологій національного технічного університету «Дніпровська політехніка» (м. Дніпро).

Гнатушенко Володимир Володимирович - д.т.н., професор, професор кафедри інформаційних систем та технологій національного технічного університету «Дніпровська політехніка» (м. Дніпро).

Гаркуша Игорь Николаевич - к.т.н., доцент, доцент кафедры информационных систем и технологий национального технического университета «Днепровская политехника» (г. Днепр).

Гнатушенко Владимир Владимирович - д.т.н., профессор, профессор кафедры информационных систем и технологий национального технического университета «Днепровская политехника» (г. Днепр).

Garkusha Igor - Ph.D. in technical science, assistant professor of department of information systems and technologies, Dnipro University of Technology, Dnipro, Ukraine.

Hnatushenko Volodymyr - doctor of technical science, professor, professor of department of information systems and technologies, Dnipro University of Technology, Dnipro, Ukraine. 